\title{
Preparation of Ionic Silsesquioxanes with Regular Structures and Their Hybridization
}

\author{
Yoshiro Kaneko, ${ }^{1}$ Hisaya Toyodome, ${ }^{1}$ Miki Shoiriki, ${ }^{1}$ and Nobuo Iyi $^{2}$ \\ ${ }^{1}$ Graduate School of Science and Engineering, Kagoshima University, 1-21-40 Korimoto, Kagoshima 890-0065, Japan \\ ${ }^{2}$ Functional Geomaterials Group, National Institute for Materials Science (NIMS), 1-1 Namiki, Tsukuba 305-0044, Japan \\ Correspondence should be addressed to Yoshiro Kaneko, ykaneko@eng.kagoshima-u.ac.jp
}

Received 19 June 2012; Accepted 22 August 2012

Academic Editor: Maki Itoh

Copyright (C) 2012 Yoshiro Kaneko et al. This is an open access article distributed under the Creative Commons Attribution License, which permits unrestricted use, distribution, and reproduction in any medium, provided the original work is properly cited.

\begin{abstract}
This paper deals with our recent studies on the preparation of ionic silsesquioxanes (SQs) with regular structures. Cationic ladderlike polySQs (PSQs) with hexagonally stacked structures were successfully prepared by the sol-gel reactions of amino groupcontaining organotrialkoxysilanes in strong acid aqueous solutions. Self-organization of an ion pair (a salt) prepared from the amino group in the organotrialkoxysilane and an acid is the key factor for the formation of such regular structures of the PSQs. It is also reported that the control of the conformational structure of the PSQs was performed by the introduction of the chiral moieties. In addition, we investigated the correlation between the $\mathrm{p} K_{\mathrm{a}} \mathrm{s}$ of acid-catalysts and the structures of SQs prepared by the hydrolytic condensation of amino group-containing organotrialkoxysilane, that is, the use of the superacid aqueous solution resulted in the formation of cage-like octaSQ, while the ladder-like PSQs with hexagonally stacked structures were formed from the strong acid aqueous solutions under the same reaction conditions. Furthermore, anion-exchange behaviors of the cationic ladder-like PSQ were investigated with various organic and inorganic compounds, such as anionic surfactants, a polymer, and layered clay minerals, to obtain the functional hybrid materials.
\end{abstract}

\section{Introduction}

Silsesquioxanes (SQs), the materials containing the structure of $\mathrm{RSiO}_{1.5}$, have attracted much attention in the research fields of organic-inorganic hybrid materials for academic and application reasons $[1,2]$ because they can contain the various functional groups as side-chains (R) and are inorganic materials indicating the remarkable compatibility with organic materials such as polymers [3-6], in addition to exhibiting superior thermal, mechanical, and chemical stabilities derived from siloxane ( $\mathrm{Si}-\mathrm{O}-\mathrm{Si}$ ) bond frameworks with high bond energy compared with $\mathrm{C}-\mathrm{C}$ bonds.

However, even though various kinds of polyhedral oligomeric SQs (POSS) are known as SQs with controlled molecular structures (Scheme 1(a)) [7-12], the regularly structured polySQs (PSQs) have only been obtained in the limited cases. This is because PSQs are prepared by polycondensation of the trifunctional silane monomers such as organotrialkoxysilanes and organotrichlorosilanes. These multifunctional monomers generally result in the formation of insoluble polymers with irregular three-dimensional network structures of Si-O-Si bonds (Scheme 1(b)) [2]. If the structures of PSQs can be controlled, they are expected to be applicable for a wide range of materials research fields.

Ladder-structured PSQs are one of a few PSQs with controlled molecular structures (Scheme 1(c)) [13-17]. These structures are classified into two types: "perfect ladder structure" (Scheme 1(c-i)) and "ladder-like structure" (Scheme 1(c-ii)) [18]. The latter has slight defects in Si-O-Si bond main-chain. Even though oligomeric SQ with "perfect ladder structure" could be synthesized by a step-by-step method and its characterization methods were established [19], it is difficult to prepare PSQs with such structures and to characterize them. In most cases, the ladder-structured PSQs probably do not have "perfect ladder structure" but have "ladder-like structure" as shown in Scheme 1(c-ii).

The ladder-like PSQs exhibit rigidity and anisotropy in addition to the aforementioned superior physical properties 
<smiles>[R][R]1([H])O[Si]2([R])O[Si]3([R])O[Si]4([R])O[Si]([R])(O1)O[Si]1([R])O[Si]([R])(O2)O[Si]([R])(O3)O[Si]([R])(O4)O1</smiles>

(a) Polyhedral oligomeric SQ (POSS)

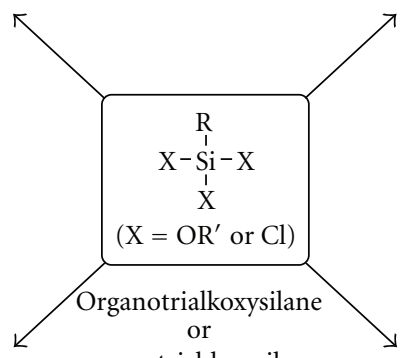

(b) Insoluble PSQ with irregular threedimensional network structure

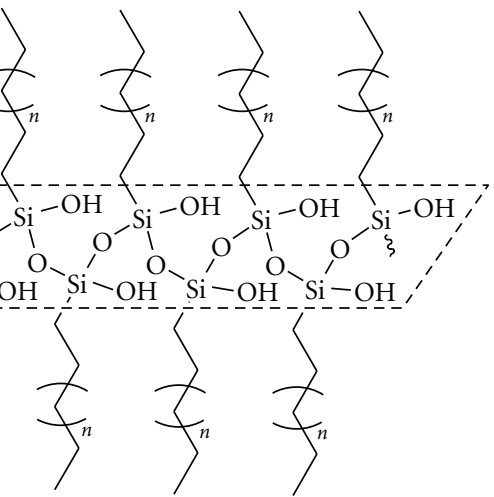

(d) Multilayered PSQ

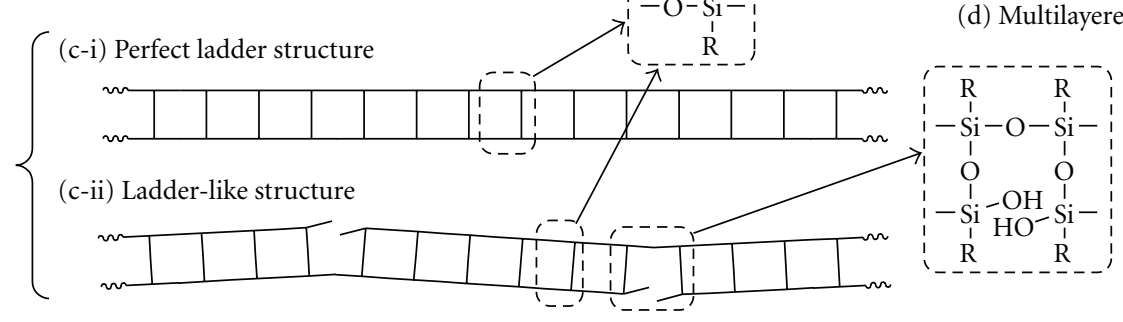

SCHEme 1: Preparation of silsesquioxanes (SQs) with various structures.

of SQs because they have one-dimensional network structures of $\mathrm{Si}-\mathrm{O}-\mathrm{Si}$ bonds. Furthermore, ladder-like PSQs are colorless materials due to no absorptions of $\mathrm{Si}-\mathrm{O}-\mathrm{Si}$ bonds in the visible light region and can be used as transparent solutions owing to good solubility in any solvents. These properties of ladder-like PSQs would be useful for versatile applications, in particular, as inorganic compounds due to hybridization with organic functional materials.

Furthermore, the control of the higher-ordered structures (nanostructures) of PSQs would also be significant to apply to various supramolecular organic-inorganic hybrid materials. For example, it has been reported that trifunctional silane monomers containing long alkyl chains were hydrolyzed to form amphiphilic molecules having silanol groups, resulting in the formation of multilayered PSQs by polycondensation (Scheme 1(d)) [20, 21]. Another method for controlling higher-ordered structures of PSQs is sol-gel reaction (hydrolytic polycondensation) of 1,4bis(trialkoxysilyl)benzene as a monomer in the presence of surfactants [22]. The resulting material has a hexagonal array of mesopores and crystal-like frameworks. Self-organization of long alkyl chains by hydrophobic interactions is a driving force to form such regular higher-ordered structures.

From the aforementioned background, it is evident that the development of PSQs with regularly controlled molecular and higher-ordered structures is one of the important issues for research fields of SQs. Therefore, the present paper reviews our recent researches on the preparation of ionic PSQs with regular structures. In the second part, we describe the preparation of cationic ladder-like PSQs with hexagonally stacked structures by sol-gel reaction of amino group-containing organotrialkoxysilane monomers and their detailed characterizations. In the third part, the introduction of the chiral moieties into the ladder-like PSQ is described to investigate the conformational structures of the resulting PSQs. In the fourth part, we report the correlation between the $\mathrm{p} K_{\mathrm{a}}$ of acid-catalysts and the structures of cationic SQs prepared by hydrolytic condensation of an amino group-containing organotrialkoxysilane monomer. The fifth part deals with anion-exchange reactions of the 


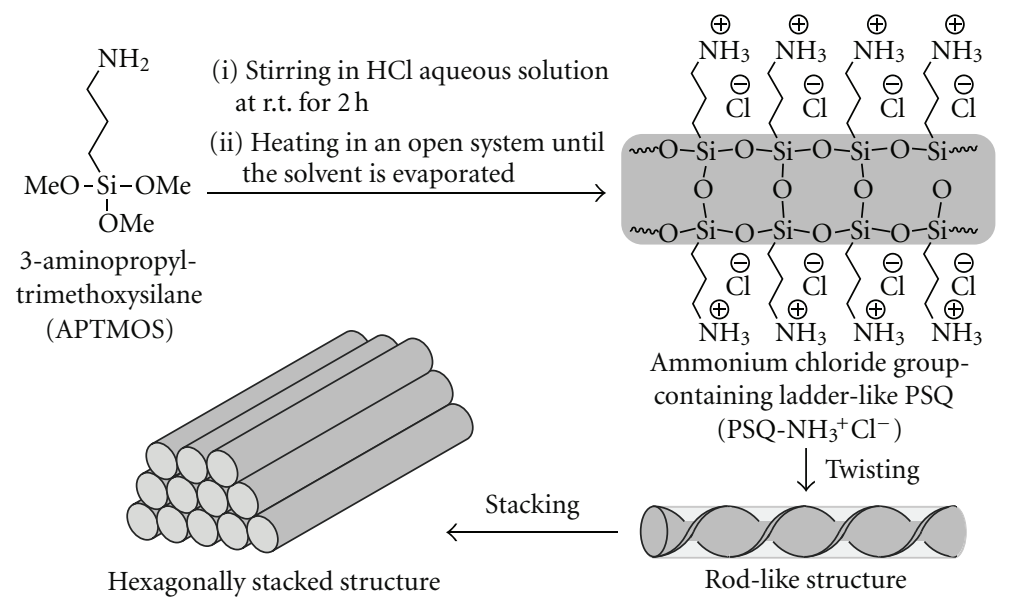

Scheme 2: Preparation of an ammonium chloride group-containing ladder-like PSQ (PSQ- $\mathrm{NH}_{3}{ }^{+} \mathrm{Cl}^{-}$) with a hexagonally stacked structure by sol-gel method.

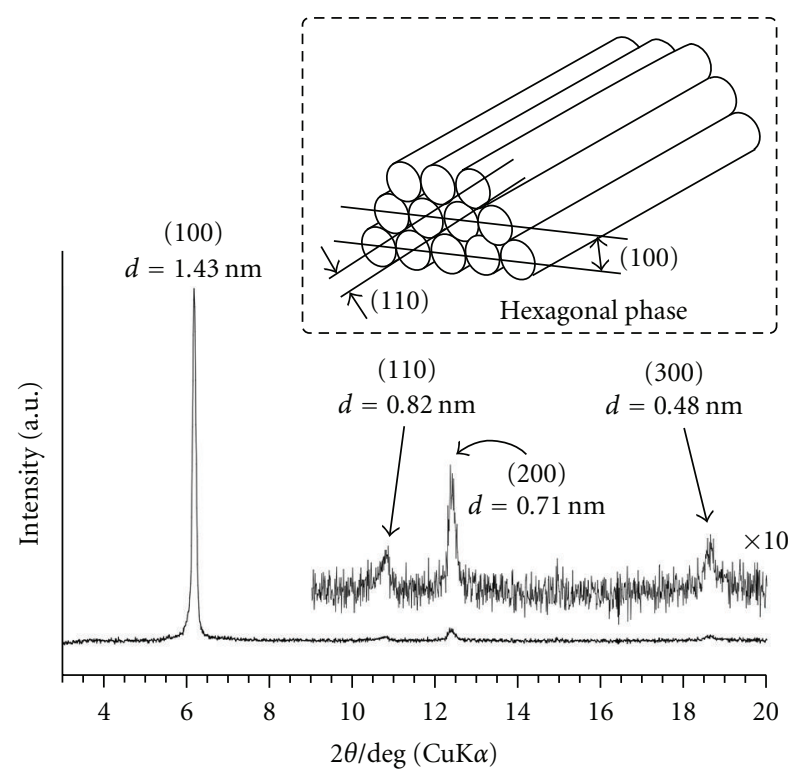

FIGURE 1: XRD pattern of PSQ- $\mathrm{NH}_{3}{ }^{+} \mathrm{Cl}^{-}$. Relative humidity (RH) during XRD measurements was $50 \%$.

cationic ladder-like PSQ with various organic and inorganic compounds, such as anionic surfactants, a polymer, and layered clay minerals, to obtain the functional hybrid materials.

\section{Preparation of Ammonium Group-Containing Ladder-Like PSQs with Hexagonally Stacked Structures}

We have developed the preparation method for ammonium group-containing PSQs with controlled molecular and higher-ordered structures by sol-gel reaction of organotrialkoxysilane monomers containing amino groups in aqueous inorganic acids [23-26].
2.1. Sol-Gel Reaction of 3-Aminopropyltrimethoxysilane. The first example of monomer to prepare the aforementioned PSQs was 3-aminopropyltrimethoxysilane (APTMOS) [23]. The sol-gel reaction of APTMOS was performed by stirring in an acid, for example, a hydrochloric acid $(\mathrm{HCl})$, aqueous solution at room temperature for $2 \mathrm{~h}$, followed by heating (ca. $\left.50-60^{\circ} \mathrm{C}\right)$ in an open system until the solvent was completely evaporated (Scheme 2 ). The resulting product was dissolved in water, and this aqueous solution was lyophilized to obtain a water-soluble ammonium chloride group-containing PSQ (PSQ- $\mathrm{NH}_{3}{ }^{+} \mathrm{Cl}^{-}$). Here, a feed molar ratio of $\mathrm{HCl}$ to APTMOS is a very important factor for the formation of the regular structures of the PSQ, that is, $\mathrm{HCl} / \mathrm{APTMOS}$ ratio needs more than one. The higherordered structure of the product was mainly characterized by the X-ray diffraction (XRD) measurements, while the molecular structure was discussed using the results of ${ }^{29} \mathrm{Si}$ NMR, XRD, and static light-scattering (SLS) measurements.

The XRD pattern of the cast film prepared by drying PSQ- $\mathrm{NH}_{3}{ }^{+} \mathrm{Cl}^{-}$aqueous solution showed diffraction peaks with the $d$-value ratio of $1: 1 / \sqrt{ } 3: 1 / 2: 1 / 3$, strongly indicating that PSQ- $\mathrm{NH}_{3}{ }^{+} \mathrm{Cl}^{-}$had a hexagonal phase (Figure 1). These peaks were assigned to the (100), (110), (200), and (300) peaks, respectively. However, based on only these data, it could not be determined whether this hexagonal phase originated from a porous-type structure or a stacking of rod-like polymers. Therefore, the influence of relative humidity (RH) was investigated on the $d$-value in the XRD measurements of PSQ- $\mathrm{NH}_{3}{ }^{+} \mathrm{Cl}^{-}$. As shown in Figure 2, the diffraction peaks shifted by varying $\mathrm{RH}$ that is, the $d$-value increased for a high $\mathrm{RH}$ and decreased for a low $\mathrm{RH}$ although the $d$-value ratios of $(110) /(100)$ and $(200) /(100)$ did not change. Such a behavior cannot be expected for hexagonalstructured porous materials. Therefore, we assumed that this hexagonal phase originated from the stacking of rod-like polymers.

We next discuss the molecular structure of PSQ$\mathrm{NH}_{3}{ }^{+} \mathrm{Cl}^{-}$. The analysis method to prove ladder structure of oligoSQs has already been established [19]. Because 


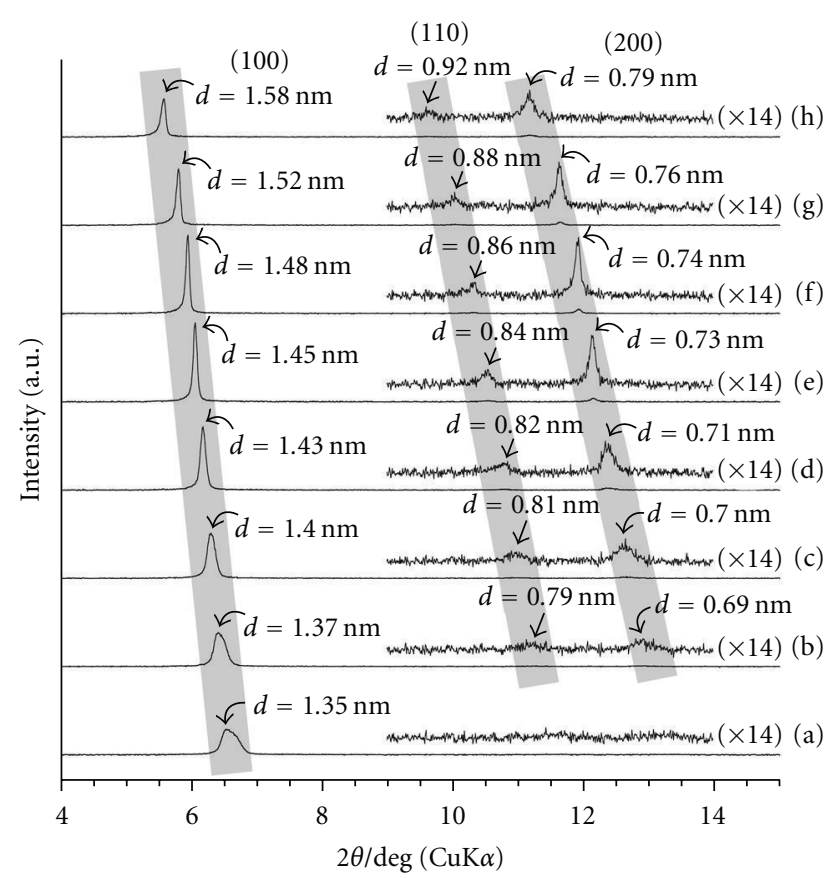

FIGURE 2: XRD patterns of PSQ- $\mathrm{NH}_{3}{ }^{+} \mathrm{Cl}^{-}$under various $\mathrm{RH}$ conditions: (a) 20, (b) 30, (c) 40, (d) 50, (e) 60, (f) 70, (g) 80, and (h) $90 \% \mathrm{RH}$. Amount of each product on glass was $c a .2 .0 \mathrm{mg} / \mathrm{cm}^{2}$.

this material forms a single crystal, its ladder structure can be confirmed by single crystal XRD measurements. In addition, the formation of ladder structure of oligoSQs can be discussed by IR spectra because the theoretical absorption peaks have been calculated [27]. On the other hand, decisive analysis methods for the ladder-like structure of PSQ have not yet been established. This is because it is difficult to obtain the single crystal of PSQ and to calculate the theoretical absorption peaks in IR spectra due to high molecular weight. Therefore, the evidence necessary to confirm the molecular structure was collected by performing multiple analyses. The ladder-like PSQ simultaneously satisfies the following conditions: (i) to be soluble in solvents, (ii) relatively high molecular weight, (iii) relatively small width of the molecule, and (iv) observation of large $\mathrm{T}^{3}$ peak and small $\mathrm{T}^{2}$ peak in ${ }^{29} \mathrm{Si}$ NMR spectrum.

PSQ- $\mathrm{NH}_{3}{ }^{+} \mathrm{Cl}^{-}$had a rod-like structure with relatively small diameter, that is, short molecular width (ca. 1.6$1.7 \mathrm{~nm}$, estimated from $d$-value of (100) peak in XRD pattern of Figure 1), in spite of forming highly dense Si-O-Si bond network structure, which was confirmed by the observation of large $\mathrm{T}^{3}$ peak in the ${ }^{29} \mathrm{Si}$ NMR spectrum of Figure 3. In addition, PSQ- $\mathrm{NH}_{3}{ }^{+} \mathrm{Cl}^{-}$was soluble in water, despite its $M_{w}$ was relatively high (ca. 12000, estimated by Zimm plot method using the SLS in water), which indicated no formation of three-dimensional network structure. These results satisfy the aforementioned conditions. All these things considered, it is reasonable to assume that the present PSQ has one-dimensional ladder-like molecular structure as shown in Scheme 1(c-ii).

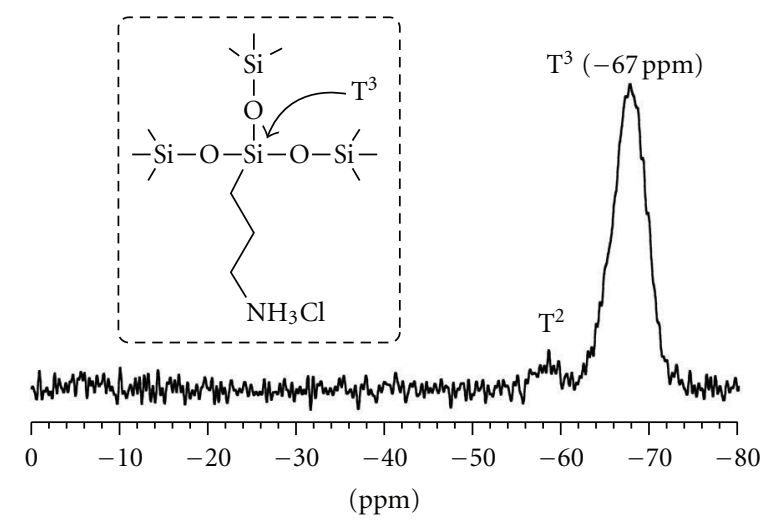

FIGURE 3: Solid-state ${ }^{29} \mathrm{Si}$ NMR spectrum of PSQ- $\mathrm{NH}_{3}{ }^{+} \mathrm{Cl}^{-}$.

We supposed that ladder-like PSQ- $\mathrm{NH}_{3}{ }^{+} \mathrm{Cl}^{-}$was twisted to form rigid rod-like structure in the solid state, resulting in the formation of the hexagonally stacked structure. The driving force for the formation of the twisted conformation is probably intramolecular charge repulsion between the ammonium cations in side-chain groups of PSQ- $\mathrm{NH}_{3}{ }^{+} \mathrm{Cl}^{-}$. Therefore, to investigate correlation between intramolecular charge repulsion and regular structure of PSQ- $\mathrm{NH}_{3}{ }^{+} \mathrm{Cl}^{-}$, the XRD measurements were performed with changing RH. Stability of the ammonium cations is affected with RH because of hydration with water molecules. The XRD patterns of PSQ- $\mathrm{NH}_{3}{ }^{+} \mathrm{Cl}^{-}$with $\mathrm{RH}$ higher than $30 \%$ indicated three diffraction peaks derived from hexagonal phase (Figures 2(b)-2(h)), meanwhile those with RH lower than $20 \%$ did not show such the diffraction peaks (Figure 2(a)). Because these results indicate the presence of correlation between the formation of the hexagonally stacked structure and higher $\mathrm{RH}$, it is assumed that the twisted structure caused by intramolecular charge repulsion between the ammonium cations is plausible conformation of PSQ- $\mathrm{NH}_{3}{ }^{+} \mathrm{Cl}^{-}$.

When the sol-gel reaction of APTMOS was performed under alkaline conditions using ammonia $\left(\mathrm{NH}_{3}\right)$ aqueous solution, insoluble PSQ with three-dimensional network structure was prepared. On the basis of all results as described above, we considered that self-organization of the ion pair prepared from the amino group of APTMOS and the acid was the driving force for the formation of regular molecular and higher-ordered structures of the PSQ.

\subsection{Sol-Gel Reaction of (3-(2-Aminoethylamino)propyl)-} trimethoxysilane. As another monomer, organotrialkoxysilane containing two amino groups, that is, (3-(2-aminoethylamino)propyl)trimethoxysilane (AEAPTMOS), was employed for the preparation of regular-structured PSQ [24]. The procedure for sol-gel reaction of AEAPTMOS was similar to that of APTMOS.

The XRD pattern of the resulting product film showed three diffraction peaks with the $d$-value ratio of $1: 1 / \sqrt{ } 3: 1 / 2$, indicating that the product had a hexagonal phase. The $d$ values of the diffraction peaks changed by varying the $\mathrm{RH}$, although the $d$-value ratios of $(110) /(100)$ and $(200) /(100)$ did not change (Table 1). The same behavior was observed 
TABLE 1: $d$-Values of diffraction peaks in the XRD patterns of the PSQ obtained from AEAPTMOS under various RH conditions.

\begin{tabular}{lccc}
\hline RH $(\%)$ & \multicolumn{3}{c}{$\begin{array}{c}\text {-value }(\mathrm{nm}) \\
(110)\end{array}$} \\
\hline 20 & $(100)$ & 0.97 & 0.84 \\
30 & 1.68 & 1.01 & 0.87 \\
40 & 1.74 & 1.04 & 0.89 \\
50 & 1.80 & 1.07 & 0.93 \\
60 & 1.85 & 1.12 & 0.97 \\
70 & 1.93 & 1.16 & 0.99 \\
80 & 2.00 & 1.20 & 1.03 \\
90 & 2.06 & - & - \\
\hline
\end{tabular}

with the aforementioned PSQ- $\mathrm{NH}_{3}{ }^{+} \mathrm{Cl}^{-}$(Figure 2). Therefore, the PSQ containing double-ammonium groups in one repeating unit also had a hexagonal phase, which originated from the stacking of rod-like polymers. The $d$-value of (100) peak of this PSQ (1.85 $\mathrm{nm}$ for RH of ca. 50\%) was larger than that of PSQ- $\mathrm{NH}_{3}{ }^{+} \mathrm{Cl}^{-}$(1.43 nm for $\mathrm{RH}$ of $c a$. $\left.50 \%\right)$. This is because of difference in side-chain lengths between these PSQs.

\section{Preparation of Ladder-Like PSQs Containing Chiral and Ammonium Chloride Side-Chain Groups}

In the previous part, we described the assumption that the ladder-like PSQ was twisted to form the rod-like structure, resulting in the formation of the hexagonally stacked structure. However, the twisting direction would not be controlled, that is, the twisted ladder-like PSQ was probably obtained in racemic form. We suppose that controlling the conformational structure of the PSQ, for example, formation of the chiral conformation that is motif for biological macromolecules such as DNA, protein, and amylose, is one of the important subjects. Such a conformational structure of the biological macromolecules is generally caused by chiral moieties of monomer units. In this part, therefore, the introduction of the chiral moieties into the ladder-like PSQs is described to control not only the molecular and higherordered structures of PSQs but also their conformational structures.

3.1. Preparation by Copolymerization Method. To prepare chiral ladder-like PSQs, the introduction of the chiral moieties into the PSQs was first investigated by acidcatalyzed copolycondensation of two organotrialkoxysilanes containing chiral and amino groups, respectively [28]. The chiral trialkoxysilanes ( $\mathrm{R}$ and $\mathrm{S}$ monomers) were synthesized by reaction of 3-(triethoxysilyl)propyl isocyanate with $(\mathrm{R})$ $(+)$ - or (S)-(-)-1-phenylethylamine in dichloromethane at room temperature for $15 \mathrm{~min}$, respectively, followed by evaporation of the dichloromethane. The sol-gel copolycondensation of the resulting chiral trialkoxysilanes with 3-aminopropyltriethoxysilane (APTEOS) (feed molar ratio
$=1: 9$ ) was performed in a mixed solvent of aqueous hydrochloric acid and methanol by heating in an open system until the solvent was completely evaporated (Scheme 3(a)).

The compositional ratio of the chiral groups to the ammonium chloride groups in the products was calculated to be 6:94 from the ${ }^{1} \mathrm{H}$ NMR spectra. Therefore, the resulting PSQs are denoted as $\mathrm{R}_{6-}$ and $\mathrm{S}_{6}$-PSQs, according to the stereostructure and functionality of the chiral groups. In the IR spectra of $\mathrm{R}_{6}$ - and $\mathrm{S}_{6}$-PSQs, large absorption bands at 1135 and $1040 \mathrm{~cm}^{-1}$ assigned to the $\mathrm{Si}-\mathrm{O}-\mathrm{Si}$ bonds were observed. In addition, the ${ }^{29} \mathrm{Si}$ NMR spectra in DMSO$d_{6}$ at $40^{\circ} \mathrm{C}$ of these PSQs exhibited the large peaks in the regions of $\mathrm{T}^{3}$. These results indicate the complete progress of sol-gel copolycondensation of the chiral trialkoxysilanes and APTEOS, and the formation of Si-O-Si bonds. The $M_{w}$ s of $\mathrm{R}_{6}-$ and $\mathrm{S}_{6}$-PSQs estimated by the Zimm plot method using SLS in water were assessed to be 10700 and 9800, respectively, indicating that the products were not oligomeric compounds but polymers.

The XRD patterns of the films of $\mathrm{R}_{6}-$ and $\mathrm{S}_{6}-\mathrm{PSQ} s$ showed three diffraction peaks with the $d$-value ratio of $1: 1 / \sqrt{ } 3: 1 / 2$, indicating the formation of the hexagonal phases. Because these PSQs were soluble in water and DMSO, it was supposed that these hexagonal phases originated from the stacking of rod-like polymers. The diameters of the rodlike PSQs calculated from $d$-values of (100) peaks (1.47$1.48 \mathrm{~nm}$ ) were assessed to be $c a .1 .7 \mathrm{~nm}$.

As aforementioned, $\mathrm{R}_{6}$ - and $\mathrm{S}_{6}$-PSQs had rod-like structures with relatively small diameter $(c a .1 .7 \mathrm{~nm})$ in spite of the presence of large $\mathrm{T}^{3}$ peak in the ${ }^{29} \mathrm{Si}$ NMR spectrum. In addition, these PSQs were soluble in water and DMSO, despite the $M_{w}$ s of the PSQs were relatively high (ca. 980010700). These results satisfy the aforementioned conditions for ladder-like structure of PSQ. Therefore, the present chiral PSQs would also have one-dimensional ladder-like structure as shown in Scheme 1(c-ii).

The vibrational circular dichroism (VCD) spectra of $\mathrm{R}_{6^{-}}$and $\mathrm{S}_{6}$-PSQs showed the reversed absorptions at $c a$. $1145-1165 \mathrm{~cm}^{-1}$, respectively (Figure 4), corresponding to the absorptions assigned to $\mathrm{Si}-\mathrm{O}-\mathrm{Si}$ bond of polymer mainchains. These results indicate that $\mathrm{R}_{6}-$ and $\mathrm{S}_{6}-\mathrm{PSQ}$ s had chiral conformations of main-chains.

3.2. Preparation by Polymer Reaction Method. To prepare ladder-like PSQs containing higher compositional ratios of chiral side-chain groups, the aforementioned acid-catalyzed copolycondensation was investigated with a higher feed molar ratio of chiral trialkoxysilanes (>20\%). However, the resulting PSQs were insoluble in all solvents owing to the formation of three-dimensional cross-linked network structures. This is because the number of ion pairs formed by the amino groups of APTEOS and the acid-catalysts decreased. Therefore, to prepare soluble ladder-like PSQs containing higher ratio of chiral groups, that is, a lower ratio of ammonium chloride groups, the polymer reaction of chiral isocyanate compounds with the aforementioned PSQ$\mathrm{NH}_{3}{ }^{+} \mathrm{Cl}^{-}$was investigated [29]. 


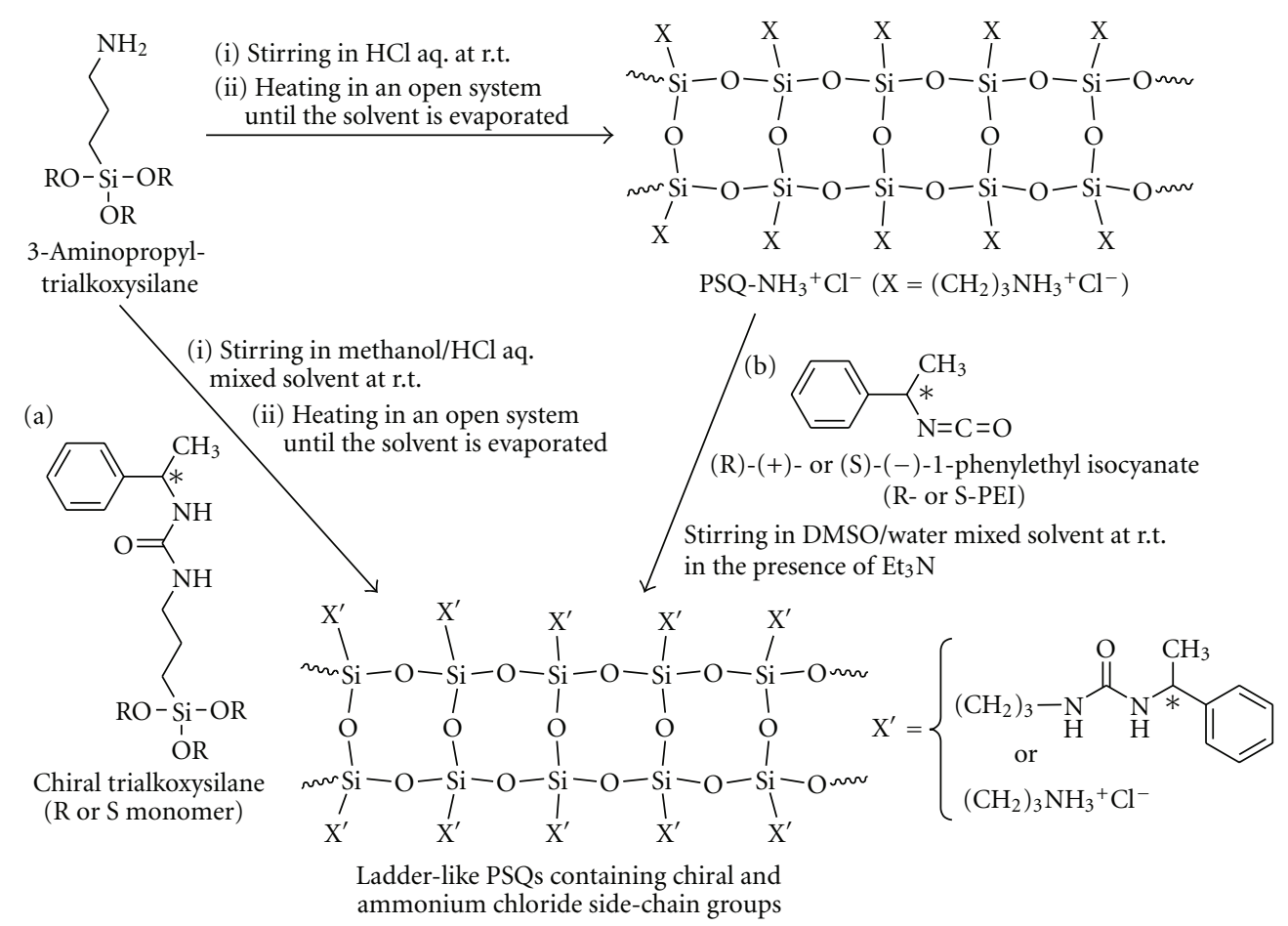

Scheme 3: Preparation of ladder-like PSQs containing chiral and ammonium chloride side-chain groups by (a) copolycondensation method and (b) polymer reaction method.

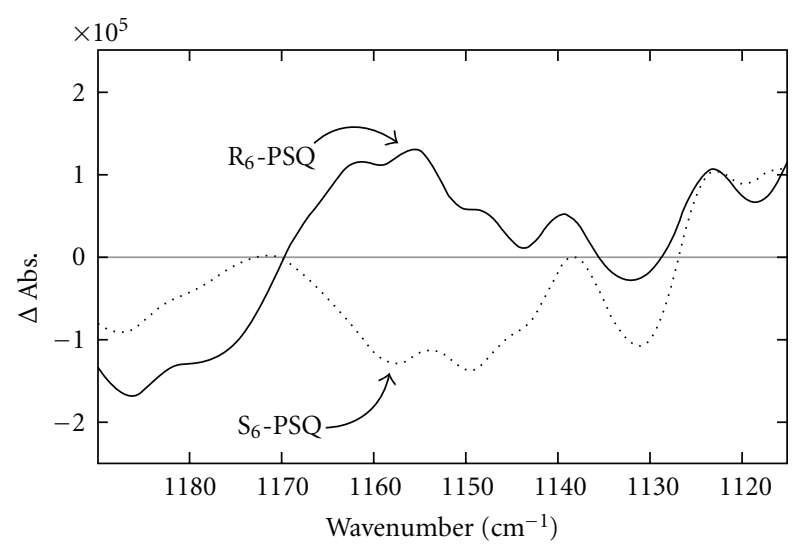

FIGURE 4: VCD spectra in DMSO of $\mathrm{R}_{6}$ - and $\mathrm{S}_{6}$-PSQs.

The preparation was performed by reaction of (R)$(+)$ - or (S)-(-)-1-phenylethyl isocyanate (R- or S-PEI) with PSQ- $\mathrm{NH}_{3}{ }^{+} \mathrm{Cl}^{-}$in the presence of triethylamine in $\mathrm{DMSO} /$ water mixed solvent at room temperature for $10 \mathrm{~min}$ (Scheme 3(b)). The compositional ratios of chiral groups to ammonium chloride groups in the resulting products were estimated from their ${ }^{1} \mathrm{H}$ NMR spectra and were found to depend on the feed molar ratio of PEI to ammonium chloride group of PSQ- $\mathrm{NH}_{3}{ }^{+} \mathrm{Cl}^{-}$. Here, soluble PSQs with the compositional ratio of chiral groups to ammonium chloride groups $=c a$. 80:20 were prepared. These PSQs are denoted as $\mathrm{R}_{80^{-}}$and $\mathrm{S}_{80}$-PSQs, respectively. The $M_{w}$ s of $\mathrm{R}_{80^{-}}$ and $S_{80}$-PSQs were estimated by the Zimm plot method using
SLS in methanol and were assessed to be $c a .54000$ and 46000, respectively.

The diffraction peaks in the XRD patterns of the PSQs were broadened compared with those of PSQ- $\mathrm{NH}_{3}{ }^{+} \mathrm{Cl}^{-}$. This is due to the decrease in the number of ion pairs, that is, ammonium chloride groups. As described above, the ion pair has an important role in the construction of a regular higher-ordered structure. However, because the XRD pattern of the product film showed diffraction peaks with $d$-value of $1.80 \mathrm{~nm}$, indicating a relatively regular stacking structure, the rigid structures of PSQs would be maintained.

The chiral conformations of many kinds of helical polymers are stabilized by intramolecular interaction, for example, hydrogen bonding [30]. Therefore, specific rotations of these polymers are generally changed by varying the solvents because their intramolecular interactions are affected by the nature of the solvent. The specific rotations $[\alpha]_{D}{ }^{22}$ of $\mathrm{R}_{80^{-}}$and $\mathrm{S}_{80}$-PSQs in methanol were $+17.4^{\circ}$ and $-18.9^{\circ}$, respectively, while those in DMF were $+8.6^{\circ}$ and $-8.5^{\circ}$, respectively. Because these PSQs have urea groups as side-chains, which are involved in intramolecular hydrogen bonding, their $[\alpha]_{D}{ }^{22}$ values were probably affected by solvent effects. Such a solvent effect on specific rotations indicates the presence of chiral conformations of these PSQs.

3.3. Chiral Induction Behavior from Chiral PSQ to Anionic Porphyrin Compound. Self-assembled hybrids formed by noncovalent interactions between photofunctional compounds and chiral molecules have attracted much attention because of their potential applications in circularly polarized 


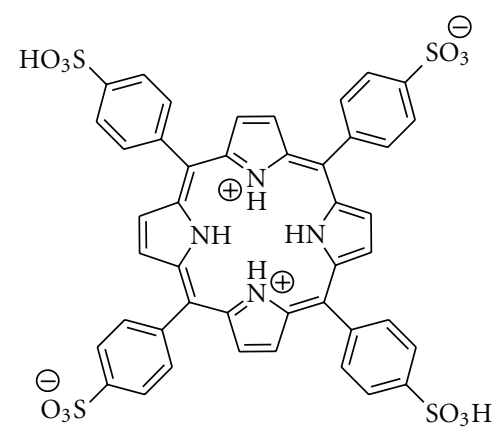

(a) TPPS

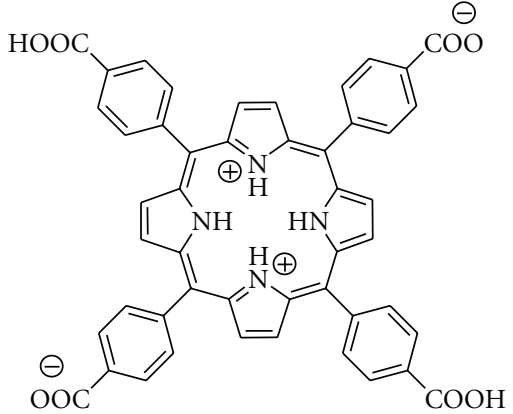

(b) TCPP

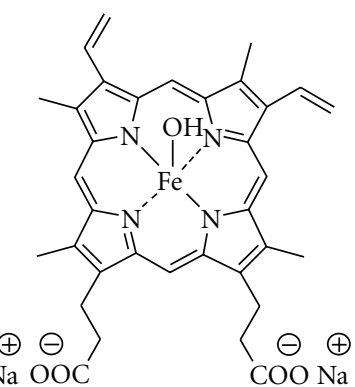

(c) Hematin sodium salt

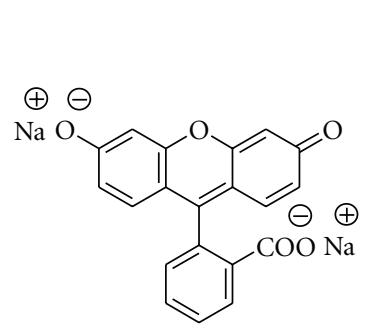

(d) Uranine

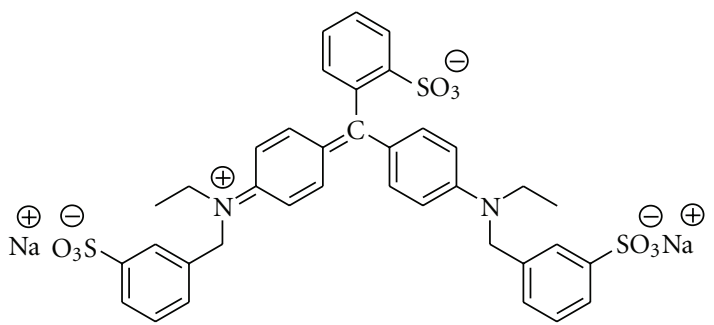

(e) Acid Blue 9

FIgURE 5: Structures of various dye compounds.

luminescent (CPL) materials. To achieve the preparation of these supramolecular hybrids by chiral induction from chiral molecules to photofunctional compounds, several combinations have been investigated, for example, anionic dye/cationic chiral surfactants [31], laser dye/cholesteric liquid crystal [32], pyrene derivatives/cyclodextrins [33], porphyrins/helical polyacetylene [34], and $\pi$-conjugated polymers/polysaccharides such as amylose [35], and schizophyllan [36]. On the other hand, there have been no reports regarding hybridization using inorganic compounds such as siloxane ( $\mathrm{SiO})$-based materials as chiral inductors. The chiral inductors derived from $\mathrm{SiO}$-based materials may enable the development of durable and thermostable hybrids with photofunctional compounds because the SiO-based materials exhibit superior thermal, mechanical, and chemical stabilities. Therefore, the aforementioned ladder-like PSQs containing chiral and ammonium groups were applied to chiral inductors for hybridization with a dye compound such as an anionic achiral porphyrin, tetraphenylporphine tetrasulfonic acid (TPPS) (Figure 5(a)), by ionic interaction $[28,29]$.

In the UV-Vis spectra of TPPS/ $\mathrm{R}_{6}$ - and $\mathrm{S}_{6}$-PSQs aqueous mixtures $(4 \mu \mathrm{mol} / \mathrm{L}$ and $100 \mu \mathrm{mol}$ unit/L, resp.), absorptions due to the Soret band of TPPS in these mixtures were blue shifted (to $400 \mathrm{~nm}$ ) compared with that of TPPS alone and indicated monomeric state with protonated (at $434 \mathrm{~nm}$ ) and deprotonated (at $414 \mathrm{~nm}$ ) species (Figure 6(a)). These results indicate that the negatively charged TPPS formed $\mathrm{H}$ aggregates along the positively charged ammonium groups as side-chains of the PSQs.

The electronic circular dichroism (ECD) spectra of these TPPS/PSQs aqueous mixtures showed the reversed absorptions due to the Soret bands of TPPS aggregates, corresponding to $\mathrm{R}_{6}$ - and $\mathrm{S}_{6}$-PSQs as templates, respectively (Figure 6(b)), indicating that TPPS aggregates have chiralities induced from the chiral PSQs. However, these mixtures did not show fluorescence emissions due to self-quenching of the excited state of the TPPS aggregate. Therefore, to inhibit the formation of $\mathrm{H}$-aggregates of TPPS by extension of the distance between the ammonium side-chains of PSQs, the same analyses were performed using $\mathrm{R}_{80}$ - and $\mathrm{S}_{80}$-PSQs as chiral inductors.

The ECD spectra of TPPS/ $\mathrm{R}_{80}$ - and $\mathrm{S}_{80}$-PSQs mixtures in methanol $(4 \mu \mathrm{mol} / \mathrm{L}$ and $100 \mu \mathrm{mol}$ unit/L, resp.) exhibited the reverse absorptions (Figure 6(d)), corresponding to the absorptions assigned to the Soret bands of TPPS at $418 \mathrm{~nm}$ in the UV-Vis spectrum (Figure 6(c)). The absorption wavelength of this mixture was almost the same as that of dilute methanol solution of sole TPPS (concentration $=4 \mu \mathrm{mol} / \mathrm{L}$ ), indicating that TPPS maintained the monomeric state in the mixture. These results indicate that the chiral induction from PSQs to TPPS was achieved without the formation of $\mathrm{H}$ aggregate of TPPS. In the present mixture, because of no formation of $\mathrm{H}$-aggregate, the fluorescence spectrum excited at $420 \mathrm{~nm}$ showed an emission peak at $654 \mathrm{~nm}$.

3.4. Influence of the Structures of Dye Compounds on Chiral Induction Behavior. To investigate the influence of the structures of dye compounds on the aforementioned chiral induction behavior, we performed the ECD and UVVis measurements of the mixtures in methanol of $R_{80^{-}}$ and $\mathrm{S}_{80}$-PSQs with various dye compounds as shown in Figure 5. When tetrakis(4-carboxyphenyl)porphyrin (TCPP) (Figure 5(b)) was used as a dye compound, the reverse absorptions assigned to TCPP in these mixtures were observed in the ECD spectra (Figure 7(b)). These behaviors 


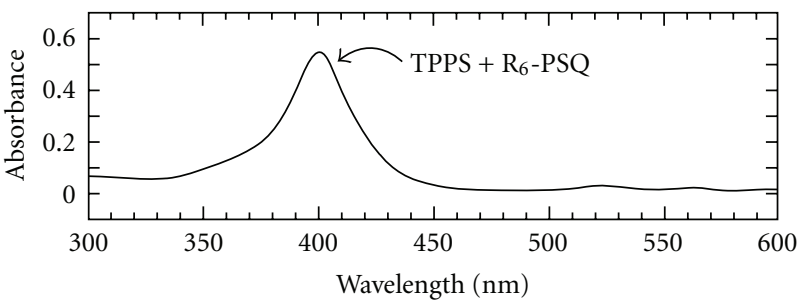

(a)

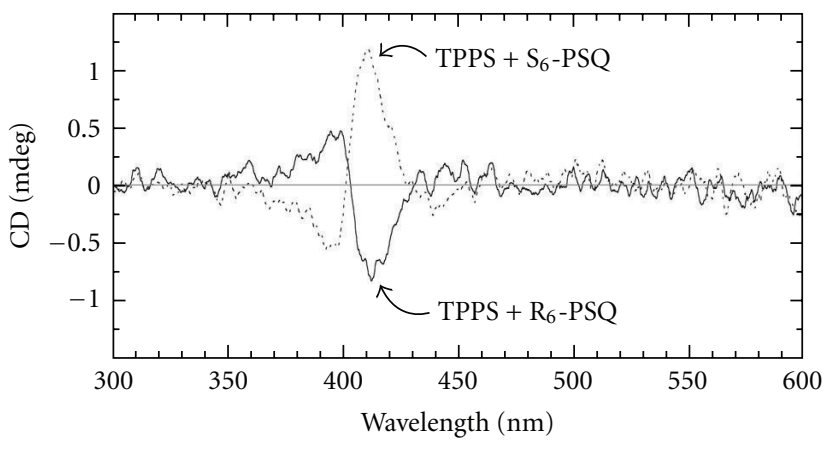

(b)

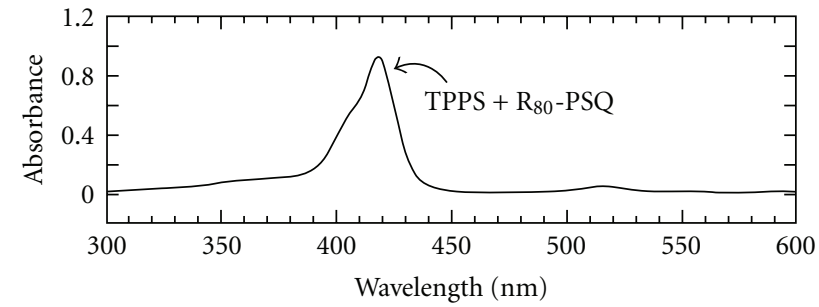

(c)

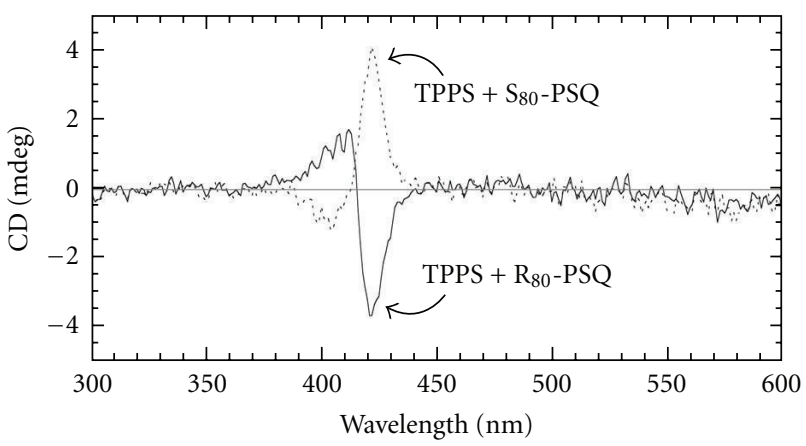

(d)

FIGURE 6: (a) UV-Vis spectrum of TPPS/R $_{6}$-PSQ aqueous mixture, (b) ECD spectra of TPPS/R - $^{-}$and $\mathrm{S}_{6}$-PSQs aqueous mixtures, (c) UV-Vis spectrum of TPPS/ $R_{80}$-PSQ mixture in methanol, and (d) ECD spectra of TPPS/R $/ \mathrm{R}_{80}$ - and $\mathrm{S}_{80}$-PSQs mixtures in methanol.

were similar to those using TPPS and indicated that the chiral induction from PSQs to TCPP was occurred. On the other hand, such the absorptions in the ECD spectra did not appear using Hematin sodium salt (Figure 5(c)), Uranine (Figure 5(d)), and Acid Blue 9 (Figure 5(e)) as dye compounds (Figures 7(d), 7(f), and 7(h)). Difference in the structures between the dye compounds indicated chiral induction (TPPS and TCPP) and the others (Hematin sodium salt, Uranine, and Acid Blue 9) are point symmetry, that is, the former had point-symmetric structure and the later did not have it. Therefore, we assumed that point symmetry of dye compounds was an important factor for the chiral induction behavior from $\mathrm{R}_{80^{-}}$and $\mathrm{S}_{80}$-PSQs to these dye compounds.

\section{Correlation between the $\mathrm{p} K_{\mathrm{a}}$ of Acid-Catalysts and the Structures of SQs Prepared by Hydrolytic Condensation of APTMOS}

As described above, the sol-gel reaction of APTMOS using $\mathrm{HCl}$ aqueous solution resulted in the formation of ladder-like PSQ with hexagonally stacked structure [23-26]. Furthermore, when another acid, for example, nitric acid $\left(\mathrm{HNO}_{3}\right)$ aqueous solution was used, we confirmed the formation of similarly structured PSQ [23]. On the other hand, when the hydrolytic condensation of APTMOS was performed using a superacid trifluoromethanesulfonic acid $\left(\mathrm{CF}_{3} \mathrm{SO}_{3} \mathrm{H}\right)$ aqueous solution under the same reaction conditions as those used for the preparation of the ladder-like PSQ as described above, we found that cage-like octa(3-aminopropyl)SQ trifluoromethanesulfonate (OAP-POSS- $\mathrm{CF}_{3} \mathrm{SO}_{3}$ ) was prepared in $c a .93 \%$ yield with a total reaction time of $c a .5-6 \mathrm{~h}$ (Scheme 4) [37]. In the preparation of OAP-POSS, these values are considerably high yield and a short reaction time compared with those of the previous studies [7-9].

For the confirmation of the OAP-POSS- $\mathrm{CF}_{3} \mathrm{SO}_{3}$ structure as shown in Scheme 4 , the ${ }^{29} \mathrm{Si}$ NMR, matrix-assisted laser desorption ionization time of flight mass (MALDITOF MS), electrospray ionization mass (ESI MS), and IR measurements were carried out. The ${ }^{29} \mathrm{Si}$ NMR spectrum in DMSO- $d_{6}$ at $40^{\circ} \mathrm{C}$ of the product showed only a $\mathrm{T}^{3}$ signal at $c a .-66 \mathrm{ppm}$. This indicates that the product has only one type of $\mathrm{Si}$ atoms, which are substituted with three siloxane bonds (i.e., the absence of a silanol group). Furthermore, in the MALDI-TOF MS spectrum of the product, only one significant peak was observed, which corresponded to the mass of OAP-POSS without $\mathrm{CF}_{3} \mathrm{SO}_{3}{ }^{-}$ as counterions $\left(\mathrm{m} / z 881.9[\mathrm{M}+\mathrm{H}]^{+}\right)$. To support the mass result from the MALDI-TOF MS spectrum, we performed an ESI MS measurement of the product. Consequently, peaks corresponding to the mass of OAP-POSS were also observed. Additionally, the counterions of the product were exchanged (from $\mathrm{CF}_{3} \mathrm{SO}_{3}{ }^{-}$to $\mathrm{Cl}^{-}$) by treatment with the mixed solvent of $0.5 \mathrm{~mol} / \mathrm{L}$ methanolic $\mathrm{HCl}$ and acetone to more easily evaluate the $\mathrm{Si}-\mathrm{O}-\mathrm{Si}$ stretching absorption band in the IR spectrum. The IR spectrum of the product with $\mathrm{Cl}^{-}$as the counterion showed only one absorption peak at $1125 \mathrm{~cm}^{-1}$ derived from $\mathrm{Si}-\mathrm{O}-\mathrm{Si}$ bonds. It has been reported that the IR spectra of cage-like octaSQs showed a single peak due to the $\mathrm{Si}-\mathrm{O}-\mathrm{Si}$ stretching absorption band because of their highly symmetrical structures [27]. From these results, it was 


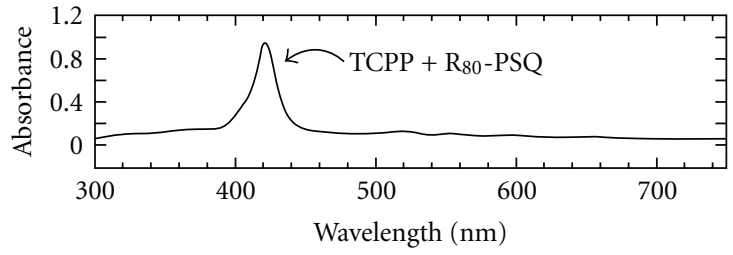

(a)

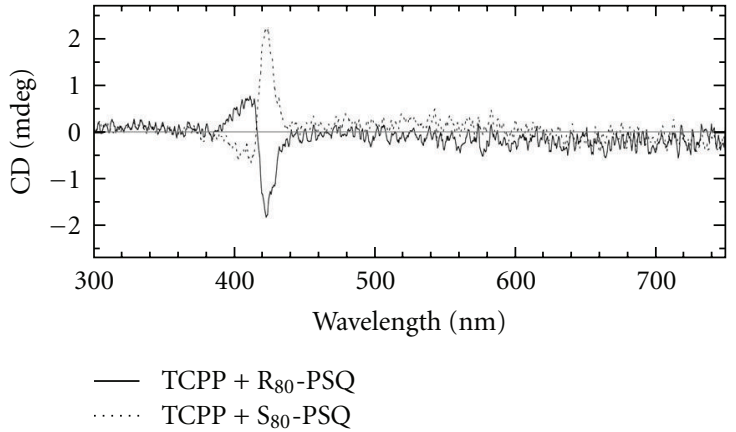

(b)

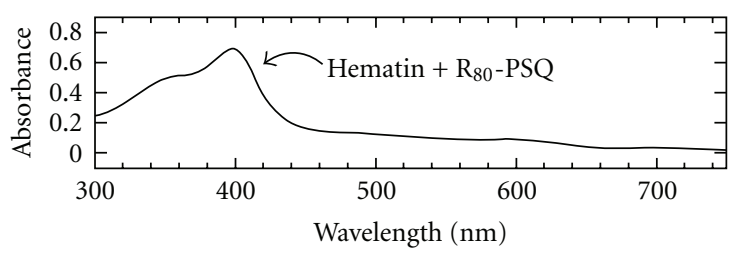

(c)

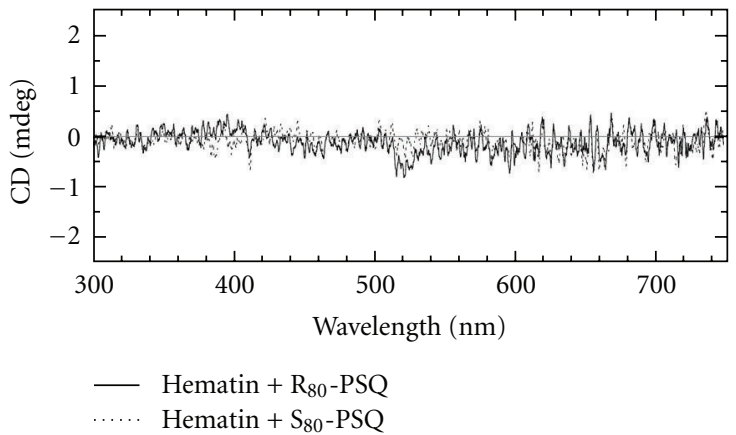

(d)

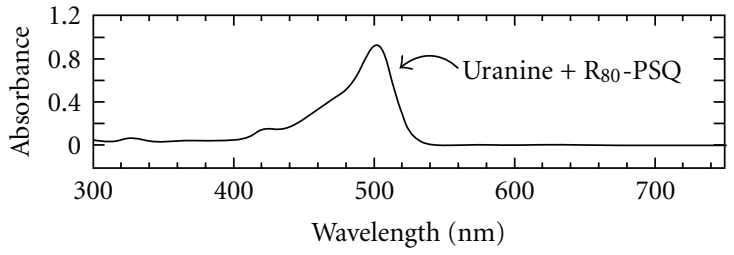

(e)

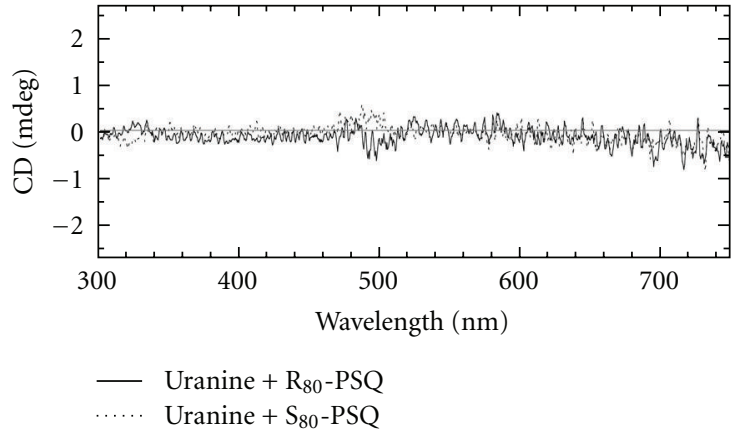

(f)

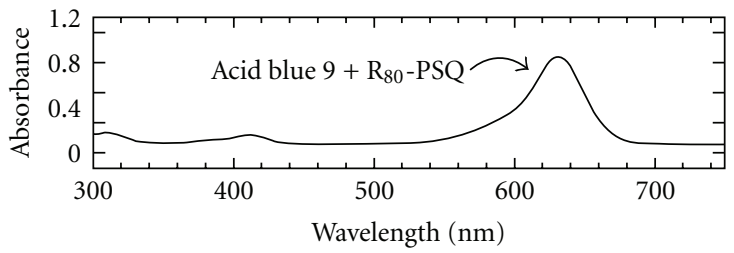

(g)

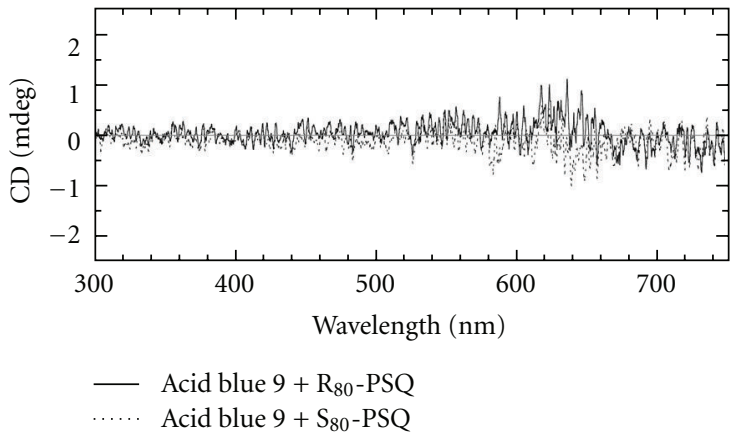

(h)

FIGURE 7: (a) UV-Vis spectrum of TCPP/R $\mathrm{R}_{80}$-PSQ mixture, (b) ECD spectra of TCPP/R $\mathrm{R}_{80}$ - and $\mathrm{S}_{80}$-PSQs mixtures, (c) UV-Vis spectrum of Hematin/ $R_{80}$-PSQ mixture, (d) ECD spectra of Hematin/ $R_{80}$ and $S_{80}$-PSQs mixtures, (e) UV-Vis spectrum of Uranine/ $R_{80}$-PSQ mixture, (f) ECD spectra of Uranine $/ R_{80}$ - and $S_{80}$-PSQs mixtures, (g) UV-Vis spectrum of Acid Blue 9/R $_{80}$-PSQ mixture, and (h) ECD spectra of Acid Blue $9 / R_{80}$ - and $S_{80}$-PSQs mixtures. In all cases, methanol was employed as a solvent, and the molar ratios of dye compound to one unit of PSQ were $1: 25$.

concluded that the product had cage-like structure as shown in Scheme 4.

As aforementioned, the ladder-like PSQs with hexagonally stacked structures can be prepared from APTMOS using the strong acids such as $\mathrm{HCl}$ and $\mathrm{HNO}_{3}$ aqueous solutions under the same reaction conditions as those used for the preparation of OAP-POSS- $\mathrm{CF}_{3} \mathrm{SO}_{3}$. The differences between the $\mathrm{CF}_{3} \mathrm{SO}_{3} \mathrm{H}\left(\mathrm{p} K_{\mathrm{a}}=-13\right)$ and the acids used for the formation of the ladder-like PSQs $\left(\mathrm{HCl}\right.$ and $\mathrm{HNO}_{3}, \mathrm{p} K_{\mathrm{a}} \mathrm{s}$ $=-3.7$ and -1.8 , resp.) are associated with their acidity and bulkiness. The $\mathrm{p} K_{\mathrm{a}}$ of trifluoroacetic acid $\left(\mathrm{CF}_{3} \mathrm{COOH}, \mathrm{p} K_{\mathrm{a}}\right.$ $=0.3$ ) is higher than that of $\mathrm{CF}_{3} \mathrm{SO}_{3} \mathrm{H}$ (i.e., the acidity of $\mathrm{CF}_{3} \mathrm{COOH}$ is lower than that of $\mathrm{CF}_{3} \mathrm{SO}_{3} \mathrm{H}$ ) although the bulkiness of both acids is similar. Therefore, to investigate the effect of these properties of the acids on the structures of the synthesized SQs, the hydrolytic condensation of APTMOS was performed using $\mathrm{CF}_{3} \mathrm{COOH}$ aqueous solution. Consequently, we found that a hexagonally structured PSQ was obtained, as confirmed by XRD measurements. In addition, the ${ }^{29} \mathrm{Si}$ NMR spectrum showed a slight $\mathrm{T}^{2}$ peak, indicating 


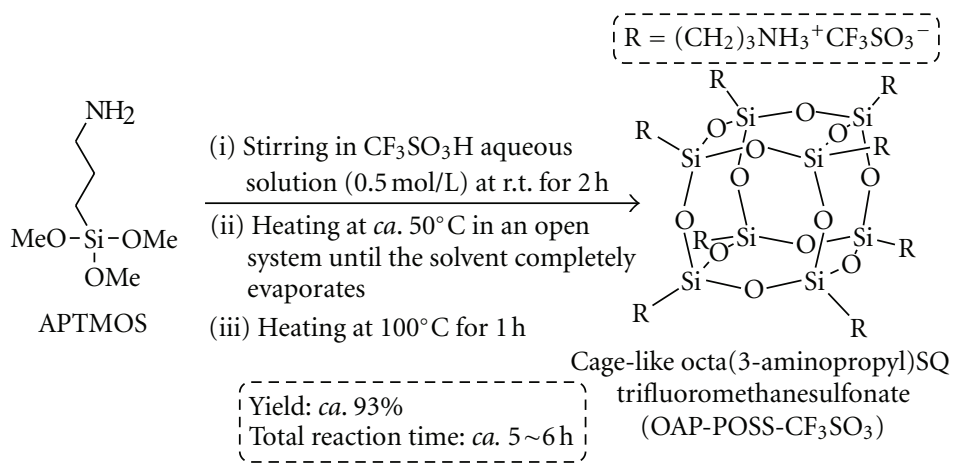

SCheme 4: Preparation of OAP-POSS- $\mathrm{CF}_{3} \mathrm{SO}_{3}$ using $\mathrm{CF}_{3} \mathrm{SO}_{3} \mathrm{H}$ aqueous solution in higher yield with a shorter reaction time.

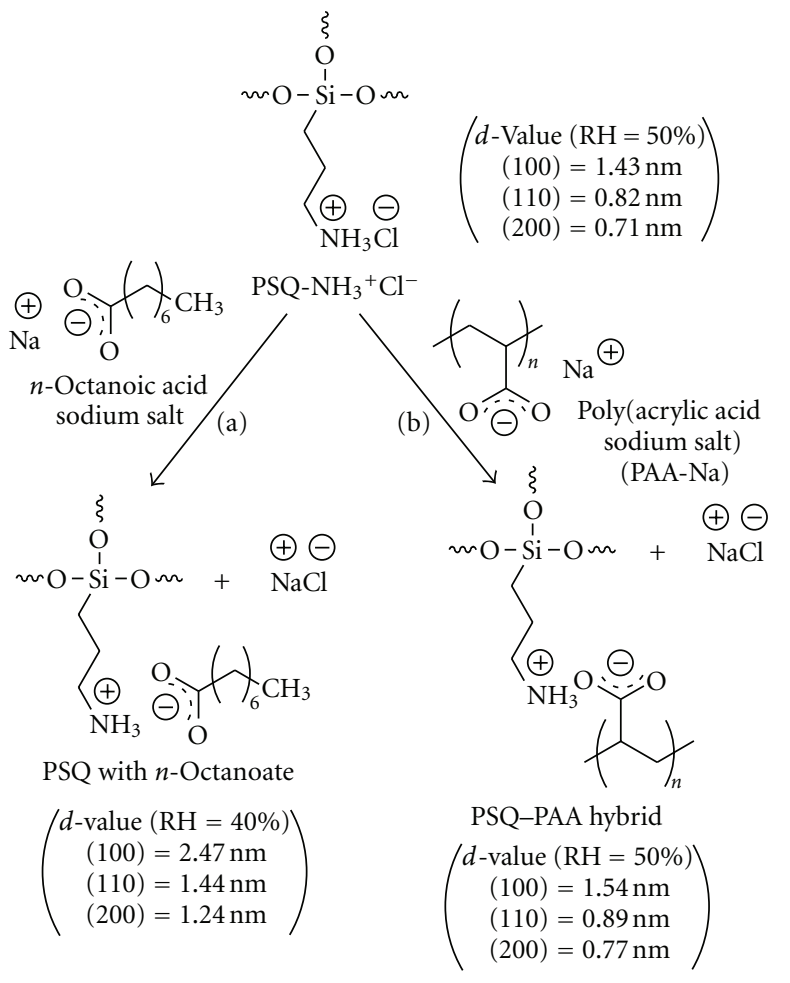

Scheme 5: Ion-exchange reactions of PSQ- $\mathrm{NH}_{3}{ }^{+} \mathrm{Cl}^{-}$with (a) $n$ octanoic acid sodium salt and (b) poly(acrylic acid sodium salt).

that there was no formation of the OAP-POSS- $\mathrm{CF}_{3} \mathrm{SO}_{3}$ structure, which was confirmed by the presence of silanol groups. These results indicate that the lower $\mathrm{p} K_{\mathrm{a}}$ of the acid is an important factor for the preparation of OAP-POSS$\mathrm{CF}_{3} \mathrm{SO}_{3}$.

On the basis of these results, we concluded that the $\mathrm{p} K_{\mathrm{a}}$ of the acids was important to control the structures of SQs prepared by hydrolytic condensation of APTMOS, that is, the use of the superacid aqueous solution resulted in the formation of cage-like octaSQ, while the ladder-like PSQs with hexagonally stacked structures were formed from the strong acid aqueous solutions under the same reaction conditions (Figure 8). Detailed studies on the hydrolytic condensations of APTMOS using other acid-catalysts with various $\mathrm{p} K_{\mathrm{a}}$ levels are now in progress.

\section{Ion-Exchange Behaviors of Cationic Ladder-Like PSQs with Various Anionic Compounds}

Because the aforementioned PSQ- $\mathrm{NH}_{3}{ }^{+} \mathrm{Cl}^{-}$has ammonium groups as side-chains and chloride anions $\left(\mathrm{Cl}^{-}\right)$as counterions, the anion-exchange property can be expected. Therefore, ion-exchange reactions of the PSQs were performed with various anionic compounds.

5.1. Ion-Exchange with Fatty Acids. First, a fatty acid salt such as $n$-octanoic acid sodium salt was employed as an anionic compound (Scheme 5(a)) [23]. By pouring PSQ- $\mathrm{NH}_{3}{ }^{+} \mathrm{Cl}^{-}$ aqueous solution into aqueous solution of $n$-octanoic acid sodium salt, precipitation immediately occurred. The XRD pattern of the resulting water-insoluble product showed peaks for a typical hexagonal phase and the $d$-value of (100) peak increase more than those of the original PSQs (PSQ$\mathrm{NH}_{3}{ }^{+} \mathrm{Cl}^{-}$), indicating that the diameter of the rod-like PSQ increased when the $\mathrm{Cl}^{-}$as the counterion was exchanged with the bulky $n$-octanoate. Thus, the hexagonal phase of the rod-like PSQ was maintained, in spite of the increase in the $d$-value by the ion-exchange reaction with $n$-octanoic acid sodium salt.

On the other hand, when the ion-exchange reactions were performed using the fatty acid salts containing longer alkyl chains ( $n$-decanoic acid sodium salt, $n$-dodecanoic acid sodium salt, and $n$-tetradecanoic acid sodium salt), the peaks due to the typical hexagonal phase were not obtained. This is because the hydrophobic interaction between the guest fatty acid salts containing longer alkyl chains was too strong to maintain the hexagonally stacked structure of rod-like PSQ.

5.2. Ion-Exchange with Anionic Organic Polymer. Hybrids composed of organic and inorganic materials usually exhibit improved performance properties compared with conventional composites, mixtures on a micrometer scale $(\mu \mathrm{m})$, due to their unique phase morphology, and improved interfacial properties. For these reasons, nanostructured 


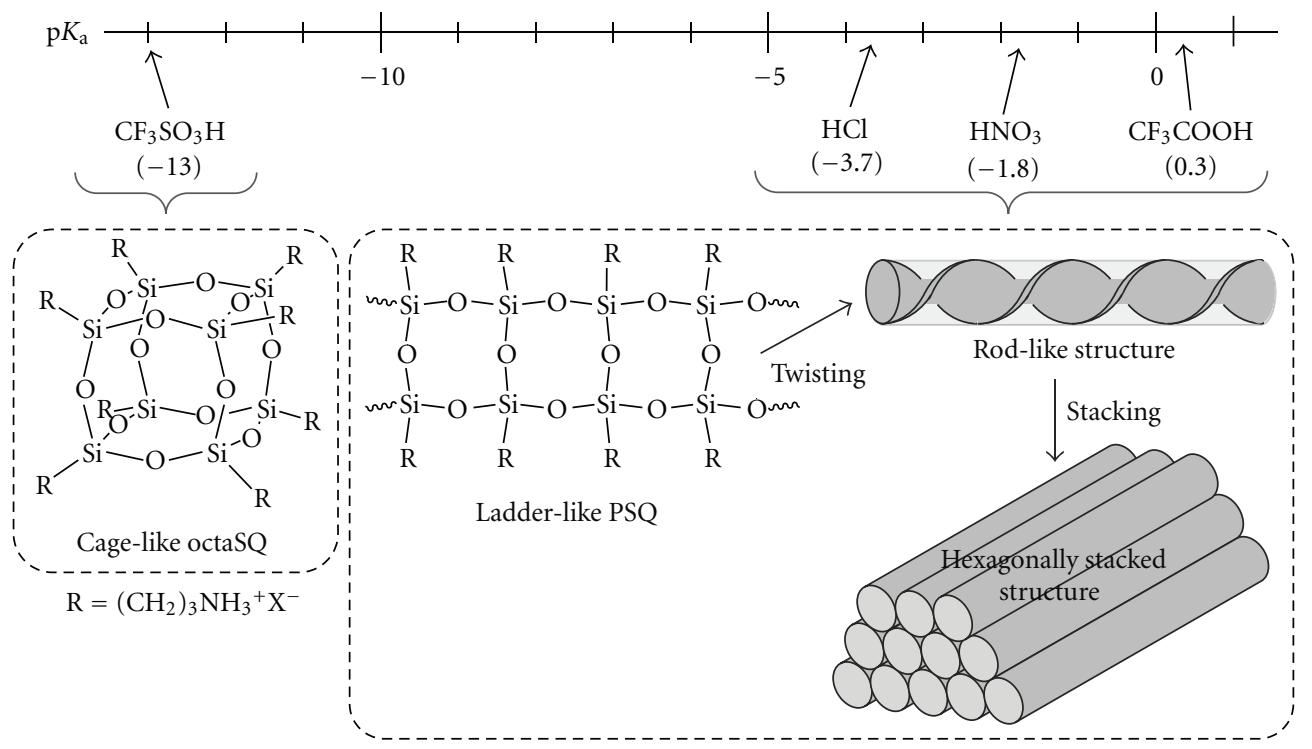

FIGURE 8: Correlation between the $\mathrm{p} K_{\mathrm{a}}$ of acid-catalysts and the structures of SQs prepared by hydrolytic condensation of APTMOS.

organic-inorganic hybrids have attracted considerable attention from both fundamental research and applications points of view $[38,39]$. In particular, the organic-inorganic hybrids obtained from the synthetic polymers as organic species are important industrial materials.

Here, we describe the preparation of an organicinorganic polymer hybrid (PSQ-PAA) with regular higherordered structure composed of the aforementioned PSQ$\mathrm{NH}_{3}{ }^{+} \mathrm{Cl}^{-}$as the inorganic species and poly(acrylic acid sodium salt) (PAA-Na) as the organic species by an ion-exchange reaction [40]. To obtain PSQ-PAA, the ion-exchange reaction was performed by pouring PSQ$\mathrm{NH}_{3}{ }^{+} \mathrm{Cl}^{-}$aqueous solution into PAA-Na aqueous solution (Scheme 5(b)).

The IR spectrum of PSQ-PAA indicated that the product consisted of both organic and inorganic polymers. The CHN elemental analysis data showed that the $\mathrm{C} / \mathrm{N}$ molar ratio for the product was 5.92. From this value, the ratio of the functional groups of the two polymers, that is, $\mathrm{NH}_{3}{ }^{+}$and $\mathrm{COO}^{-}$, was calculated to be $c a .1: 1$. The XRD pattern of PSQ-PAA showed the formation of a hexagonal phase, and the $d$-values of the diffraction peaks were different from those of PSQ- $\mathrm{NH}_{3}{ }^{+} \mathrm{Cl}^{-}$(Scheme 5(b)), indicating the formation of not a macroscopic mixture but the molecular-scale hybrid of two polymers.

5.3. Ion-Exchange with Layered Clay Minerals. There have been intense research activities on layered silicates pillared with inorganic or organic clusters, which are called pillared interlayer clays (PILCs) [41-43]. PILCs have much higher surface areas and pore volumes than those of the original clays. Such properties make them useful catalysts, ionexchangers, and adsorbents. These materials are usually prepared by the intercalative ion-exchange of layered clay minerals with a variety of nanosized pillars, such as organic ions [44], inorganic ions [45], and sol particles [46].
Even though the preparation of various polymer/clay hybrids has already been reported [47], there have been a few studies on the preparation of PILCs using polymers. Because the polymers generally have a flexible structure, expansion of the interlayer space of clays by polymer incorporation is not enough for providing more free space.

The aforementioned PSQ- $\mathrm{NH}_{3}{ }^{+} \mathrm{Cl}^{-}$has motivated us to develop new PILCs, because PSQ- $\mathrm{NH}_{3}{ }^{+} \mathrm{Cl}^{-}$has rigidity and bulkiness to expand the interlayer of clays and ability to intercalate molecules into the interlayer of anionic clays by the ion-exchange reaction due to the presence of ammonium cations in side-chains of PSQ- $\mathrm{NH}_{3}{ }^{+} \mathrm{Cl}^{-}$. Therefore, we describe the preparation of a clay pillared with rod-like cationic PSQ- $\mathrm{NH}_{3}{ }^{+} \mathrm{Cl}^{-}[48]$.

The preparation was performed by pouring PSQ$\mathrm{NH}_{3}{ }^{+} \mathrm{Cl}^{-}$aqueous solution into an aqueous suspension of Na-saturated saponite (Na-SAP) as a clay mineral to obtain the clay pillared with PSQ- $\mathrm{NH}_{3}{ }^{+} \mathrm{Cl}^{-}$(PSQ-SAP) (Scheme 6). The resulting product was mainly characterized by IR, XRD, and nitrogen adsorption-desorption isotherm measurements.

The IR spectrum of PSQ-SAP showed the absorption assigned to the ammonium ion of the PSQ component, indicating that the PSQ was inserted into the interlayer of SAP. The XRD pattern of PSQ-SAP was completely different from that of Na-SAP and PSQ- $\mathrm{NH}_{3}{ }^{+} \mathrm{Cl}^{-}$. Accordingly, PSQSAP was not a mixture, but an intercalated nanoorder material, that is, a hybrid.

From the nitrogen adsorption-desorption isotherms at $77 \mathrm{~K}$, the surface area and pore volume of PSQ-SAP derived from the $t$-plot were estimated to be $370 \mathrm{~m}^{2} / \mathrm{g}$ and $0.15 \mathrm{~cm}^{3} / \mathrm{g}$, respectively. This indicates that a porous material was prepared from the starting materials with dense structures (BET surface areas of Na-SAP and PSQ- $\mathrm{NH}_{3}{ }^{+} \mathrm{Cl}^{-}$ were $c a .26$ and $5 \mathrm{~m}^{2} / \mathrm{g}$, resp.).

When a clay mineral with high cation-exchange capacity (CEC) such as Li-saturated taeniolite was employed, such a 


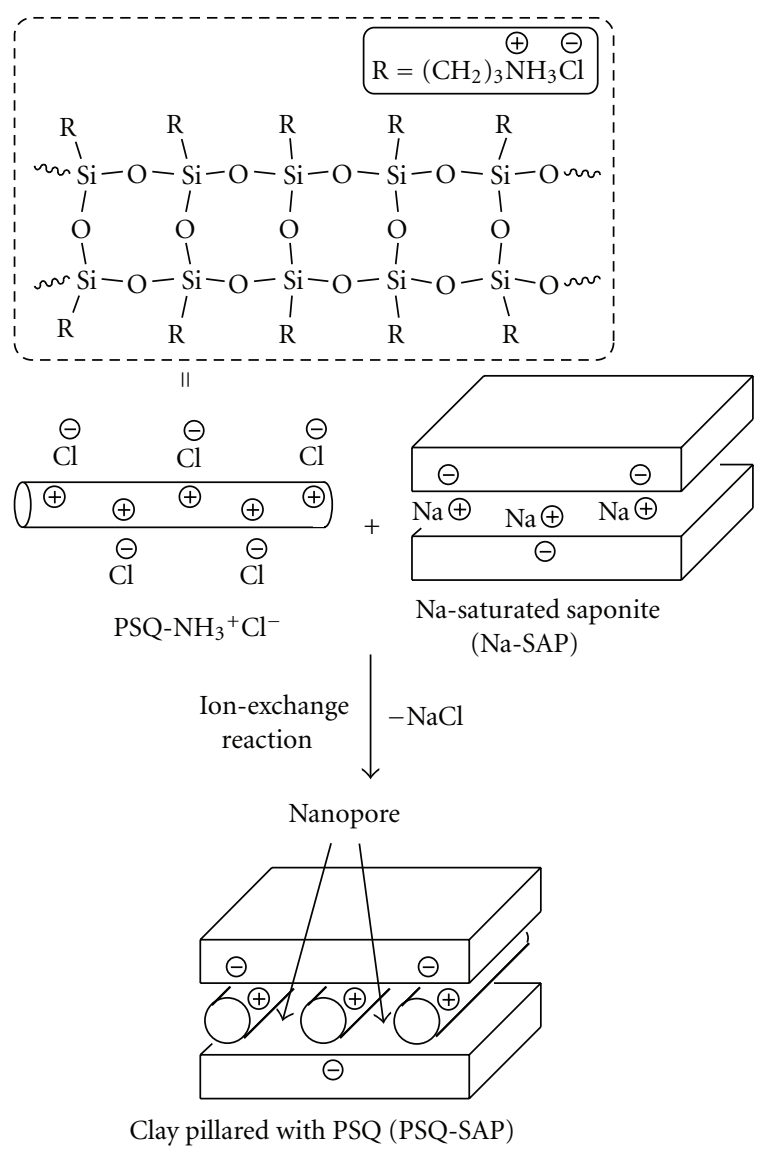

Scheme 6: Preparation of a clay pillared with PSQ by ion-exchange reaction of PSQ- $\mathrm{NH}_{3}{ }^{+} \mathrm{Cl}^{-}$with Na-saturated saponite.

porous material was not obtained by combination with PSQ$\mathrm{NH}_{3}{ }^{+} \mathrm{Cl}^{-}$(BET surface area of the resulting product was $c a$. $53 \mathrm{~m}^{2} / \mathrm{g}$ ), although a sufficient interlayer spacing existed as confirmed by the XRD measurement. Because the distance between the PSQs in the interlayer of taeniolite is short due to the higher CEC of the Li-saturated taeniolite, sufficient space was not provided. Furthermore, when polyallylamine hydrochloride (PAA-Cl), a common cationic polymer, was used for pillaring in the SAP interlayer, a porous structure was not obtained (BET surface area of the product was $c a$. $52 \mathrm{~m}^{2} / \mathrm{g}$ ). It was difficult for PAA-Cl to pillar the interlayer of SAP due to the lack of rigidity and bulkiness. From these results, it was considered that the rigidity and bulkiness of the guest polymers and a sufficient distance between charges in the host layered clay minerals are necessary for preparing clays pillared with polymers.

\section{Conclusion}

In this review, we described the preparation of cationic ladder-like PSQs with hexagonally stacked structures by the sol-gel reaction of amino group-containing organotrialkoxysilane monomers in the acid solutions. It was considered that self-organization of the ion pairs prepared from the monomers and the acids was the driving force for the formation of regular molecular and higherordered structures of the PSQs. In addition, to control the conformational structure of PSQ, the introduction of the chiral moieties into PSQ was performed. Furthermore, we found that the $\mathrm{p} K_{\mathrm{a}}$ of the acid-catalysts was important to control the structures of the ammonium group-containing SQs prepared by hydrolytic condensation of APTMOS, that is, the use of the superacid aqueous solution resulted in the formation of cage-like octaSQ, while the ladderlike PSQs with hexagonally stacked structures were formed from the strong acid aqueous solutions under the same reaction conditions. Finally, because the present ladderlike PSQs indicated the anion-exchange properties due to existence of cationic functional groups as side-chains, we described the anion-exchange behaviors with various organic and inorganic compounds, such as anionic surfactants, a polymer, and layered clay minerals, to obtain the functional hybrid materials.

\section{Acknowledgments}

This work was supported in part by a research grant from the Mazda Foundation and a Grant-in-Aid for Scientific Research (C) from Ministry of Education, Culture, Sports, Science, and Technology, Japan (no. 24550138). The authors acknowledge Prof. H. Sato of Graduate School of Science and Engineering, Ehime University (Japan) and Dr. T. Mizumo of Graduate School of Engineering, Hiroshima University (Japan) for their valuable technical advices. of a clay pillared with PSQ by ion-exchange reaction of PSQ- $\mathrm{NH}_{3}{ }^{+} \mathrm{Cl}^{-}$

\section{References}

[1] R. H. Baney, M. Itoh, A. Sakakibara, and T. Suzuki, "Silsesquioxanes," Chemical Reviews, vol. 95, no. 5, pp. 1409-1430, 1995.

[2] D. A. Loy, B. M. Baugher, C. R. Baugher, D. A. Schneider, and K. Rahimian, "Substituent effects on the sol-gel chemistry of organotrialkoxysilanes," Chemistry of Materials, vol. 12, no. 12, pp. 3624-3632, 2000.

[3] J. Choi, J. Harcup, A. F. Yee, Q. Zhu, and R. M. Laine, "Organic/inorganic hybrid composites from cubic silsesquioxanes," Journal of the American Chemical Society, vol. 123, no. 46, pp. 11420-11430, 2001.

[4] K. M. Kim and Y. Chujo, "Organic-inorganic hybrid gels having functionalized silsesquioxanes," Journal of Materials Chemistry, vol. 13, pp. 1384-1391, 2003.

[5] X. Yu, S. Zhong, X. Li et al., "A giant surfactant of polystyrene-(carboxylic acid-functionalized polyhedral oligomeric silsesquioxane) amphiphile with highly stretched polystyrene tails in micellar assemblies," Journal of the American Chemical Society, vol. 132, no. 47, pp. 16741-16744, 2010.

[6] F. Wang, X. Lu, and C. He, "Some recent developments of polyhedral oligomeric silsesquioxane (POSS)-based polymeric materials," Journal of Materials Chemistry, vol. 21, no. 9, pp. 2775-2782, 2011.

[7] F. J. Feher and K. D. Wyndham, "Amine and ester-substituted silsesquioxanes: synthesis, characterization and use as a core for starburst dendrimers," Chemical Communications, no. 3 , pp. 323-324, 1998. 
[8] R. M. Laine, C. Zhang, A. Sellinger, and L. Viculis, "Polyfunctional cubic silsesquioxanes as building blocks for organic/inorganic hybrids," Applied Organometallic Chemistry, vol. 12, no. 10-11, pp. 715-723, 1998.

[9] Z. Zhang, G. Liang, and T. Lu, "Synthesis and characterization of cage octa(aminopropylsilsesquioxane)," Journal of Applied Polymer Science, vol. 103, no. 4, pp. 2608-2614, 2007.

[10] D. B. Cordes, P. D. Lickiss, and F. Rataboul, "Recent developments in the chemistry of cubic polyhedral oligosilsesquioxanes," Chemical Reviews, vol. 110, no. 4, pp. 2081-2173, 2010.

[11] K. Tanaka, F. Ishiguro, and Y. Chujo, "POSS ionic liquid," Journal of the American Chemical Society, vol. 132, no. 50, pp. 17649-17651, 2010.

[12] K. Tanaka and Y. Chujo, "Advanced functional materials based on polyhedral oligomeric silsesquioxane (POSS)," Journal of Materials Chemistry, vol. 22, no. 5, pp. 1733-1746, 2012.

[13] J. F. Brown Jr., L. H. Vogt Jr., and P. I. Prescott, "Double chain polymers of phenylsilsesquioxane," Journal of the American Chemical Society, vol. 82, no. 23, pp. 6194-6195, 1960.

[14] J. F. Brown Jr., L. H. Vogt Jr., and P. I. Prescott, "Preparation and characterization of the lower equilibrated phenylsilsesquioxanes," Journal of the American Chemical Society, vol. 86, no. 6, pp. 1120-1125, 1964.

[15] M. Unno, S. Chang, and H. Matsumoto, "cis-trans-cistetrabromotetramethylcyclotetrasiloxane: a versatile precursor of ladder silsesquioxanes," Bulletin of the Chemical Society of Japan, vol. 78, no. 6, pp. 1105-1109, 2005.

[16] X. Zhang, P. Xie, Z. Shen et al., "Confined synthesis of a cis-isotactic ladder polysilsesquioxane by using a $\pi$ stacking and h-bonding superstructure," Angewandte Chemie-International Edition, vol. 45, no. 19, pp. 3112-3116, 2006.

[17] H. Seki, T. Kajiwara, Y. Abe, and T. Gunji, "Synthesis and structure of ladder polymethylsilsesquioxanes from silafunctionalized cyclotetrasiloxanes," Journal of Organometallic Chemistry, vol. 695, no. 9, pp. 1363-1369, 2010.

[18] Y. Abe and T. Gunji, "Oligo- and polysiloxanes," Progress in Polymer Science, vol. 29, no. 3, pp. 149-182, 2004.

[19] M. Unno, A. Suto, and H. Matsumoto, "Pentacyclic laddersiloxane," Journal of the American Chemical Society, vol. 124, no. 8, pp. 1574-1575, 2002.

[20] A. N. Parikh, M. A. Schivley, E. Koo et al., " $n$-Alkylsiloxanes: from single monolayers to layered crystals. The formation of crystalline polymers from the hydrolysis of $n$ octadecyltrichlorosilane," Journal of the American Chemical Society, vol. 119, no. 13, pp. 3135-3143, 1997.

[21] A. Shimojima, Y. Sugahara, and K. Kuroda, "Inorganicorganic layered materials derived via the hydrolysis and polycondensation of trialkoxy(alkyl)silanes," Bulletin of the Chemical Society of Japan, vol. 70, no. 11, pp. 2847-2853, 1997.

[22] S. Inagaki, S. Guan, T. Ohsuna, and O. Terasaki, "An ordered mesoporous organosilica hybrid material with a crystal-like wall structure," Nature, vol. 416, no. 6878, pp. 304-307, 2002.

[23] Y. Kaneko, N. Iyi, K. Kurashima, T. Matsumoto, T. Fujita, and K. Kitamura, "Hexagonal-structured polysiloxane material prepared by sol-gel reaction of aminoalkyltrialkoxysilane without using surfactants," Chemistry of Materials, vol. 16, no. 18, pp. 3417-3423, 2004.

[24] Y. Kaneko, N. Iyi, T. Matsumoto, and K. Kitamura, "Synthesis of rodlike polysiloxane with hexagonal phase by sol-gel reaction of organotrialkoxysilane monomer containing two amino groups," Polymer, vol. 46, no. 6, pp. 1828-1833, 2005.
[25] Y. Kaneko and N. Iyi, "Sol-gel synthesis of rodlike polysilsesquioxanes forming regular higher-ordered nanostructure," Zeitschrift für Kristallographie, vol. 222, no. 11, pp. 656-662, 2007.

[26] Y. Kaneko and N. Iyi, "Sol-gel synthesis of water-soluble polysilsesquloxanes with regular structures," Kobunshi Ronbunshu, vol. 67, no. 5, pp. 280-287, 2010.

[27] E. S. Park, H. W. Ro, C. V. Nguyen, R. L. Jaffe, and D. Y. Yoon, "Infrared spectroscopy study of microstructures of poly(silsesquioxane)s," Chemistry of Materials, vol. 20, no. 4, pp. 1548-1554, 2008.

[28] Y. Kaneko and N. Iyi, "Sol-gel synthesis of ladder polysilsesquioxanes forming chiral conformations and hexagonal stacking structures," Journal of Materials Chemistry, vol. 19, no. 38, pp. 7106-7111, 2009.

[29] Y. Kaneko, H. Toyodome, and H. Sato, "Preparation of chiral ladder-like polysilsesquioxanes and their chiral induction to anionic dye compound," Journal of Materials Chemistry, vol. 21, no. 41, pp. 16638-16641, 2011.

[30] H. Zhao, F. Sanda, and T. Masuda, "Transformation of helical sense of poly( $N$-propargylamides) controlled by competition between structurally different enantiomeric amino acids," Macromolecules, vol. 37, no. 24, pp. 8888-8892, 2004.

[31] D. Franke, M. Vos, M. Antonietti, N. A. J. M. Sommerdijk, and C. F. J. Faul, "Induced supramolecular chirality in nanostructured materials: ionic self-assembly of perylenechiral surfactant complexes," Chemistry of Materials, vol. 18, no. 7, pp. 1839-1847, 2006.

[32] M. Uchimura, Y. Watanabe, F. Araoka, J. Watanabe, H. Takezoe, and G. I. Konishi, "Development of laser dyes to realize low threshold in dye-doped cholesteric liquid crystal lasers," Advanced Materials, vol. 22, no. 40, pp. 4473-4478, 2010.

[33] K. Kano, H. Matsumoto, Y. Yoshimura, and S. Hashimoto, "Binding sites of pyrene and related compounds and chiral excimer formation in the cavities of cyclodextrins and branched cyclodextrins," Journal of the American Chemical Society, vol. 110, no. 1, pp. 204-209, 1988.

[34] H. Onouchi, T. Miyagawa, K. Morino, and E. Yashima, "Assisted formation of chiral porphyrin homoaggregates by an induced helical poly(phenylacetylene) template and their chiral memory," Angewandte Chemie-International Edition, vol. 45, no. 15, pp. 2381-2384, 2006.

[35] M. Ikeda, Y. Furusho, K. Okoshi et al., "A luminescent poly(phenylenevinylene)-amylose composite with supramolecular liquid crystallinity," Angewandte ChemieInternational Edition, vol. 45, no. 39, pp. 6491-6495, 2006.

[36] C. Li, M. Numata, A. H. Bae, K. Sakurai, and S. Shinkai, "Selfassembly of supramolecular chiral insulated molecular wire," Journal of the American Chemical Society, vol. 127, no. 13, pp. 4548-4549, 2005.

[37] Y. Kaneko, M. Shoiriki, and T. Mizumo, "Preparation of cagelike octa(3-aminopropyl)silsesquioxane trifluoromethanesulfonate in higher yield with a shorter reaction time," Journal of Materials Chemistry, vol. 22, no. 29, pp. 14475-14478, 2012.

[38] A. Usuki, Y. Kojima, M. Kawasumi et al., "Synthesis of nylon 6-clay hybrid," Journal of Materials Research, vol. 8, no. 5, pp. 1179-1184, 1993.

[39] Y. Chujo, “Organic-inorganic hybrid materials," Current Opinion in Solid State and Materials Science, vol. 1, no. 6, pp. 806811, 1996. 
[40] Y. Kaneko, N. Iyi, T. Matsumoto, and K. Kitamura, "Preparation of higher-ordered inorganic-organic nanocomposite composed of rodlike cationic polysiloxane and polyacrylate," Journal of Materials Chemistry, vol. 15, no. 15, pp. 1572-1575, 2005.

[41] K. Ohtsuka, "Preparation and properties of two-dimensional microporous pillared interlayered solids," Chemistry of Materials, vol. 9, no. 10, pp. 2039-2050, 1997.

[42] J. T. Kloprogge, "Synthesis of smectites and porous pillared clay catalysts: a review," Journal of Porous Materials, vol. 5, no. 1, pp. 5-41, 1998.

[43] Z. Ding, J. T. Kloprogge, R. L. Frost, G. Q. Lu, and H. Y. $\mathrm{Zhu}$, "Porous clays and pillared clays-based catalysts. part 2: a review of the catalytic and molecular sieve applications," Journal of Porous Materials, vol. 8, no. 4, pp. 273-293, 2001.

[44] M. Ogawa, M. Takahashi, C. Kato, and K. Kuroda, "Oriented microporous film of tetramethylammonium pillared saponite," Journal of Materials Chemistry, vol. 4, no. 4, pp. 519523, 1994.

[45] M. Pichowicz and R. Mokaya, "Stability of Pillared Clays: effect of compaction on the physicochemical properties of alpillared clays," Chemistry of Materials, vol. 16, no. 2, pp. 263269, 2004.

[46] S. Yamanaka, Y. Inoue, M. Hattori, F. Okumura, and M. Yoshikawa, "Preparation and properties of clays pillared with $\mathrm{SiO}_{2}-\mathrm{TiO}_{2}$ sol particles," Bulletin of the Chemical Society of Japan, vol. 65, no. 9, pp. 2494-2500, 1992.

[47] T. J. Pinnavaia and G. W. Beall, Polymer-Clay Nanocomposites, John Wiley and Sons, Chichester, UK, 2000.

[48] Y. Kaneko, N. Iyi, T. Matsumoto, and K. Kitamura, "Preparation of a clay pillared with rodlike cationic polysiloxane," Chemistry Letters, vol. 33, no. 11, pp. 1486-1487, 2004. 

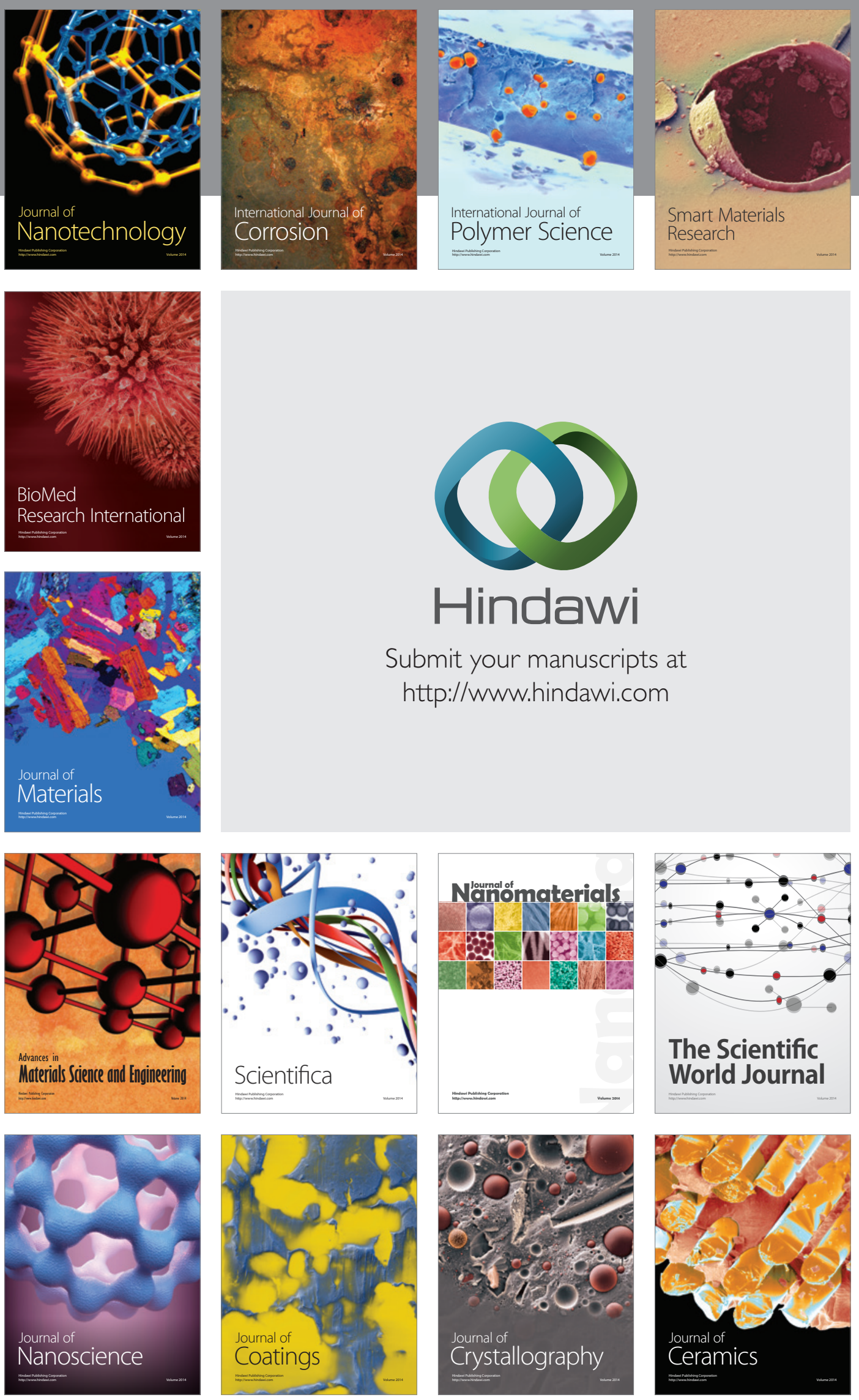

The Scientific World Journal

Submit your manuscripts at

http://www.hindawi.com

\section{World Journal}

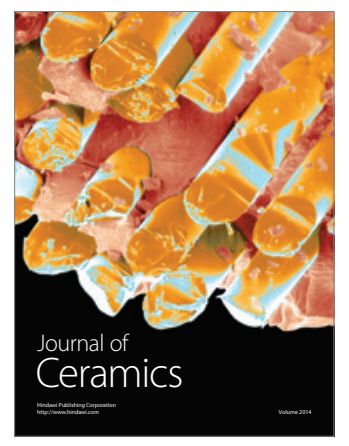

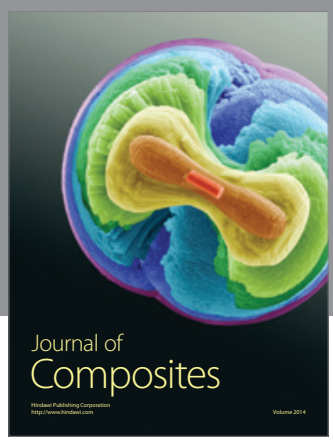
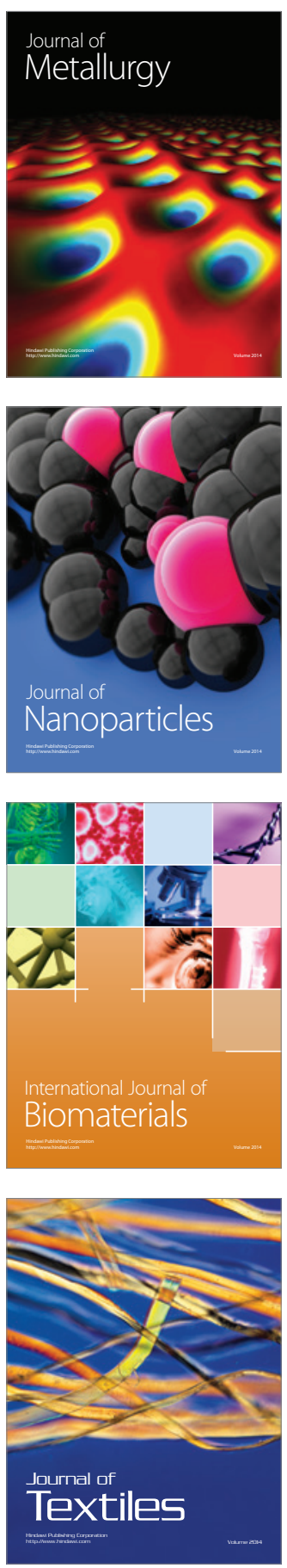